\title{
To the Editor of THE BRITISH JOURNAL OF OPHTHALMOLOGY.
}

SIR,-I have long been convinced that it is most important that myopes should never rotate their eyes downwards when reading, but that the book should be raised to the level of their eyes as explained on p. 47 of my "Prescribing of Spectacles."

Only last week a myope of $-4 \mathrm{D}$. came to me with a detachment of the retina that had occurred the previous day. He had been wearing bifocal lenses. Less than two years ago I had a similar case of $-3 D$. who had a detachment for which also I could assign no cause but that he was wearing bifocal lenses. I feel it my duty to give this warning against bifocals in myopia, though I suppose that $\mathrm{I}$ am as enthusiastic as anyone in their praise in cases of hypermetropia.

Surely Mr. Bardsley has been troubling himself over a very simple matter. If bifocal pince-nez are used, every wearer instinctively adjusts them so that his visual lines traverses them normally; and if spectacles are worn, it is a very simple matter to raise the legs a trifle so that the lenses are tilted sufficiently to meet this requirement. As when reading the head is usually inclined $10^{\circ}$ to $15^{\circ}$ the eyes need not be depressed more than $15^{\circ}$ at most.

$$
\text { I am, Sir, }
$$

Yours faithfully,

17. Claremont Place,

A. S. Percival.

NeWCASTLE-ON-Tyne.

We regret to announce the death, at the age of 62 , of Sir James Mackenzie Davidson, of London, one of the foremost authorities in the world on X-rays, especially in their applicability to ophthalmology. Formerly lecturer on ophthalmology in the University of Aberdeen and ophthalmic surgeon to the Royal Infirmary and the Royal Sick Children's Hospital, he came to London in 1897 and devoted special attention to X-ray work. He will be best remembered for his cross-thread method of localizing foreign bodies by means of X-rays, which, of course, has found its greatest application in the war. The devotion which he paid to this branch of his work impaired his vitality, and the world o science is the poorer by the loss of an inventive mind, and humanity 
by the withdrawal of a man of singularly generous nature, who never spared himself in doing good. A striking tribute was paid to him at the International Medical Congress in 1913, when it was said that his name would endure as long as X-rays were emitted from a bulb. In 1916 he accepted, without reward or rank, the office of consulting radiologist to the Military Hospitals of the

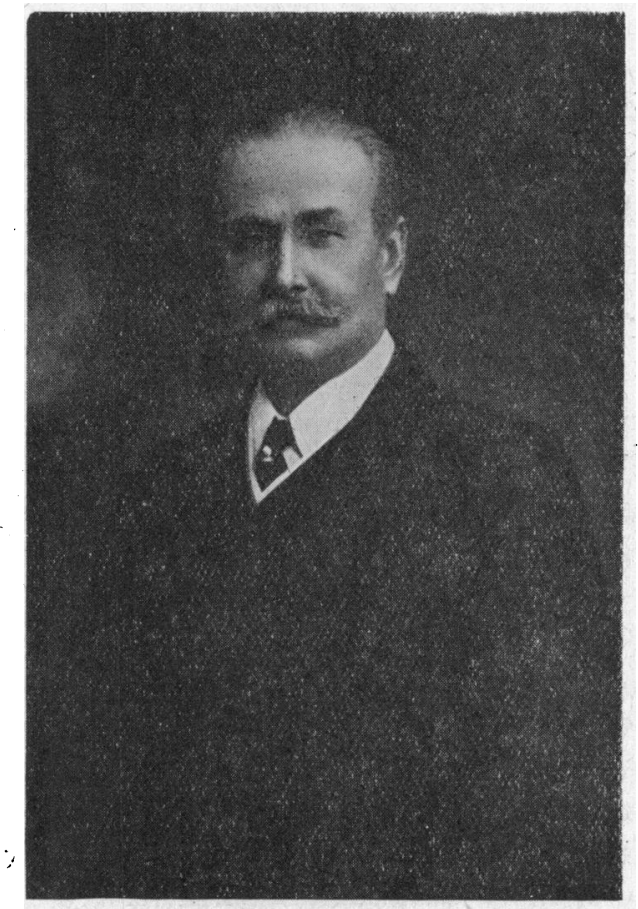

London District. Davidson was a pioneer in his application of the stereoscopic method to the viewing of X-ray pictures, and of guiding the extraction of a foreign body by means of a telephone probe. His one book, "Localization by X-rays and Stereoscopy" (1916) summed up his life-work, but such was his mental energy that it was hardly in print before he had put out of date some of the methods described by him. In civil life Sir James held the posts of consulting medical officer to the Ray Department of the Royal London Ophthalmic Hospital, and of the Charing Cross Hospital. $\mathrm{He}$ is survived by Lady Davidson, who is the sister of $\mathrm{Mr}$. J. M. Henderson, ex-M.P. for West Aberdeenshire, a son, Mr. Colin Davidson, who is Mr. Bonar Law's private secretary, and a daughter, the wife of Dr. Bernard Potter, of London. A memorial service was held on April 7 at All Souls' Church, Langham Place. 
It is but fitting that the death at 87 years of the famous scientist Sir William Crookes, O.M., should be noted in these columns. A Londoner, he began his scientific career at the old Royal College of Chemistry, Hanover Square, where he became assistant to the director, Dr. A. W. Hoffmann. He discovered thallium, invented the radiometer, and his electrical researches led up to the modern theory of the electron. He introduced the "Crookes's tube." His connection with the Royal Society was long and distinguished. Elected a Fellow in 1863, the Society awarded him three of the medals at its disposal-a Royal Medal in 1875, the Davy Medal in 1888 , and the Copley Medal in 1904; appointed him to deliver the Bakerian Lecture on three occasions; and, finally, chose him as President. While occupying this distinguished position a committee of the Royal Society was appointed to investigate the causation of glassworkers' cataract. Sir William Crookes threw himself enthusiastically into the research, more particularly with the object of discovering some glass which would protect the workmen's eyes from heat and ultra-violet radiations. He prepared a large number of glasses and investigated their properties. The best cut off most of the infra-red and ultra-violet rays while absorbing little of the luminous rays. These are the now familiar "Crookès's glasses." 